\title{
Metabolic Syndrome, Vitamin D Deficiency and Hypoadiponectinemia among Nondiabetic Patients Early after Kidney Transplantation
}

\author{
Satyarth Kulshrestha Akinlolu O. Ojo Fu L. Luan \\ Division of Nephrology, Department of Internal Medicine, University of Michigan, Ann Arbor, Mich., USA
}

\author{
Key Words \\ Adiponectin · Clinical outcomes · Kidney transplantation . \\ Metabolic syndrome $\cdot$ Vitamin D deficiency
}

\begin{abstract}
Background and Aims: Metabolic syndrome (MetS) is common among kidney transplant patients. We studied the relationship between MetS, vitamin D deficiency/insufficiency and hypoadiponectinemia early posttransplantation and their impact on clinical outcomes. Methods: Seventy-four previously nondiabetic kidney transplant patients were enrolled in a prospective cohort study between February and November 2008. Participants underwent a 2-hour oral glucose tolerance test and had their plasma levels of 25-hydroxyvitamin $\mathrm{D}(25[\mathrm{OH}] \mathrm{D})$, adiponectin, insulin, intact parathyroid hormone and lipids measured at 11 weeks posttransplantation. Clinical events including cardiovascular events, new-onset diabetes after transplantation, acute rejection, graft loss and death were recorded during the follow-up to December 2012. Results: Thirty-four study patients (45.9\%) had MetS. Patients with MetS had lower plasma concentrations of $25[\mathrm{OH}] \mathrm{D}$ ( $20.5 \pm 7.2$ vs. $24.8 \pm 11.1 \mathrm{ng} /$ $\mathrm{ml}, \mathrm{p}=0.049)$ and adiponectin ( $8.2 \pm 4.5$ vs. $14.6 \pm 8.0 \mu \mathrm{g} /$ $\mathrm{ml}, \mathrm{p}<0.0001$ ) early on, and higher composite clinical event rate $(61.8$ vs. $27.5 \%, p=0.003)$ during the follow-up. Multivariate analysis showed that the presence of MetS early after transplantation was independently associated with $25[\mathrm{OH}]$ D deficiency/insufficiency (OR: 14.0, 95\% Cl: 1.8, 107.5; $\mathrm{p}=$
\end{abstract}

0.011), depressed plasma adiponectin levels $\left(\beta-6.39, \mathrm{r}^{2}\right.$ $0.195, \mathrm{p}<0.0001$ ) and increased risk for clinical events (OR: $5.6,95 \% \mathrm{Cl}: 1.9,16.5 ; \mathrm{p}=0.002)$. Conclusion: Kidney transplant patients with MetS early after transplantation had lower levels of 25[OH]D and adiponectin, and unfavorable clinical outcomes.

Copyright $\odot 2013$ S. Karger AG, Basel

\section{Introduction}

Metabolic syndrome (MetS) is a constellation of metabolic and nonmetabolic abnormalities frequently seen among kidney transplant patients $[1,2]$. The presence of MetS is associated with inferior transplant outcomes including increased risks of new-onset diabetes mellitus after transplantation (NODAT) and cardiovascular events (CVEs), and diminished kidney transplant and patient survival [1-4].

Vitamin D deficiency and insufficiency are common in both the general and kidney transplant population and are associated with an increased risk of diabetes mellitus and cardiovascular diseases and MetS [5-8]. Adiponectin is a protein secreted exclusively by adipocytes and plays an important role in modulating insulin sensitivity, thus the risk of type 2 diabetes (T2D) [9]. Low levels of adiponectin have been also associated with glucose intolerance, T2D, early CVEs and MetS [10-14]. It is not known whether there is any relationship between vitamin $\mathrm{D}$ de-

\section{KARGER}

E-Mail karger@karger.com

www.karger.com/ajn
(C) 2013 S. Karger AG Basel

0250-8095/13/0375-0399\$38.00/0
Fu Luan, MD, MS

3914 Taubman Center, Box 5364

1500 East Medical Center Drive

Ann Arbor, MI 48109-5364 (USA)

E-Mail fluan@med.umich.edu 
ficiency/insufficiency and reduced adiponectin levels. We performed a prospective cohort study to elucidate the relationship between vitamin $\mathrm{D}$ deficiency/insufficiency, hypoadiponectinemia and MetS early after kidney transplantation, as well as their impact on overall clinical outcomes among previously nondiabetic kidney transplant patients.

\section{Materials and Methods}

Between February and November 2008, de novo kidney transplant patients without a history of diabetes prior to transplantation were enrolled in a prospective cohort study. Study participants underwent a protocol-driven 2-hour oral glucose tolerance test between weeks 10-14 post-transplantation [15]. Fasting blood plasma was collected and stored at $-80^{\circ} \mathrm{C}$. The local institutional review board approved the study.

Anthropometric parameters and baseline demographic and clinical information obtained at the time the oral glucose tolerance test was performed included height, body weight and waist circumference, BMI, blood pressure readings and the numbers of antihypertensive medications, age, gender, racial/ethnicity, renal diagnosis, family history of T2D, previous history of cardiovascular disease, the use of dialysis modalities and the duration of dialysis prior to transplantation, type of kidney transplant, number of kidney transplants, status of hepatitis $C$ serology, the presence of delayed graft function, maintenance immunosuppression regimens, and cumulative doses of corticosteroids and calcinuerin inhibitors (CNIs) up to the time of the oral glucose tolerance test. During subsequent follow-up to December 31, 2012, the clinical events including the occurrence of CVEs, new-onset diabetes mellitus after transplantation, acute rejection (AR) and kidney graft loss (including death) were documented, and final transplant function, expressed as estimated glomerular filtration rate using an abbreviated Modification of Diet in Renal Disease (MDRD) formula, was recorded.

MetS was defined according to the criteria established by the National Cholesterol Education Expert Panel III (NCEP-III) and present if a participant had at least 3 of following 5 components: fasting glucose levels of $100 \mathrm{mg} / \mathrm{dl}$ or greater, fasting triglyceride values of $150 \mathrm{mg} / \mathrm{dl}$ or greater, HDL cholesterol (HDL-C) levels of less than $40 \mathrm{mg} / \mathrm{dl}$ for males or $50 \mathrm{mg} / \mathrm{dl}$ for females, blood pressure equal or greater than 130/85 mm Hg or on antihypertensive medications, and waist circumference equal or greater than 40 and 35 inches (101.6 and $88.9 \mathrm{~cm}$ ) for males and females, respectively [16].

The measurement of 25-hydroxylvitamin D (25[OH]D), adiponectin, intact parathyroid hormone and insulin was carried out in fasting plasma through the chemistry laboratory of Michigan Diabetes Research and Training Center (MDRTC; see acknowledgment) using commercialized kits. In brief, radioimmunoassay technique was implemented for 25[OH]D (DiaSorin, Stillwater, Minn., USA), adiponectin (Millipore, Billerica, Mass., USA) and insulin (Linco Research Inc., St. Charles, Mo., USA), and chemiluminescent enzyme-labeled immunometric assay for intact parathyroid hormone (Siemens Healthcare Diagnostics Inc., Tarrytown, N.Y., USA). Insulin resistance (IR) was calculated using the homeostasis model assessment (HOMA) as HOMA-IR value [(fasting glucose level in $\mathrm{mg} / \mathrm{dl} \times$ fasting insulin level in $\mu \mathrm{U} / \mathrm{l}) / 405$ ] [17].
Table 1. Demographic and baseline parameters

\begin{tabular}{|c|c|c|c|}
\hline \multirow[t]{2}{*}{ Variables } & \multicolumn{2}{|l|}{ MetS } & \multirow[t]{2}{*}{$\mathrm{p}$} \\
\hline & yes $(n=34)$ & no $(\mathrm{n}=40)$ & \\
\hline Age, years & $47.5 \pm 13.9$ & $44.1 \pm 15.0$ & 0.32 \\
\hline Male & $24(70.6)$ & $26(65.0)$ & 0.61 \\
\hline African American & $9(26.4)$ & $13(32.5)$ & 0.57 \\
\hline BMI & $29.5 \pm 5.7$ & $26.2 \pm 4.8$ & 0.01 \\
\hline Living donor transplant & $13(38.2)$ & $24(60.0)$ & 0.06 \\
\hline First transplant & $29(85.3)$ & $36(90.0)$ & 0.72 \\
\hline Positive HCV serology & $3(8.8)$ & $3(7.5)$ & 1.00 \\
\hline Family history for T2D & $10(29.4)$ & $7(17.5)$ & 0.22 \\
\hline \multicolumn{3}{|l|}{ Smoking history } & \multirow[t]{4}{*}{0.89} \\
\hline Never & $21(61.8)$ & $24(60.0)$ & \\
\hline Former & $10(29.4)$ & $11(27.5)$ & \\
\hline Current & $3(8.8)$ & $5(12.5)$ & \\
\hline \multicolumn{3}{|l|}{ Renal diagnosis } & \multirow[t]{5}{*}{0.49} \\
\hline APKD & $5(15.2)$ & $5(12.5)$ & \\
\hline Glomerular disease & $17(51.5)$ & $14(35.0)$ & \\
\hline Hypertension & $6(17.7)$ & $9(22.5)$ & \\
\hline Others & $6(18.2)$ & $12(30.0)$ & \\
\hline \multicolumn{3}{|l|}{ Dialysis modalities } & \multirow[t]{4}{*}{0.65} \\
\hline None & $7(20.6)$ & $12(30.0)$ & \\
\hline $\mathrm{HD}$ & $5(14.7)$ & $5(12.5)$ & \\
\hline PD & $22(64.7)$ & $23(57.5)$ & \\
\hline Dialysis duration, years & $3.9 \pm 3.0$ & $2.9 \pm 2.5$ & 0.17 \\
\hline \multicolumn{4}{|l|}{ Fasting glucose at } \\
\hline transplant, $\mathrm{mg} / \mathrm{dl}$ & $86.2 \pm 9.0$ & $84.6 \pm 8.7$ & 0.46 \\
\hline CNIs: CsA & $30(88.3)$ & $33(82.5)$ & 0.64 \\
\hline \multicolumn{4}{|l|}{ Cumulative CNI doses, mg } \\
\hline CsA & $41,221 \pm 13,665$ & $35,513 \pm 11,142$ & 0.07 \\
\hline Tacro & $753 \pm 64$ & $436 \pm 66$ & 0.06 \\
\hline \multicolumn{4}{|l|}{ Cumulative prednisone } \\
\hline doses, mg & $2,521 \pm 466$ & $2,428 \pm 286$ & 0.30 \\
\hline Delayed graft function & $5(14.7)$ & $5(12.5)$ & 0.78 \\
\hline
\end{tabular}

Values are means $\pm \mathrm{SD}$ or $\mathrm{n}(\%)$. APKD $=$ Adult polycystic kidney disease; $\mathrm{HCV}=$ hepatitis $\mathrm{C}$ virus.

Continuous and categorical variables were compared using Student's t test and $\chi^{2}$ test, respectively. Multivariate regression analyses were utilized to test the association between the presence of MetS and various measured parameters including plasma $25[\mathrm{OH}] \mathrm{D}$ and adiponectin levels among others, and to correlate them with observed clinical outcomes (composite). All statistical analyses were performed using SAS 9.3. Statistical significance was set at $\mathrm{p} \leq 0.05$.

\section{Results}

There were 74 study participants with a median follow-up of 4.27 years $(3.99,4.46)$. The mean age was $46 \pm$ 16 years, $50(67.6 \%)$ were male patients and $22(29.7 \%)$ of African-American race. The prevalence of MetS was $45.9 \%(n=34)$ at a median time of 79 days $(71,89)$ posttransplantation. Table 1 shows the demographic and baseline characteristics of study participants with and 

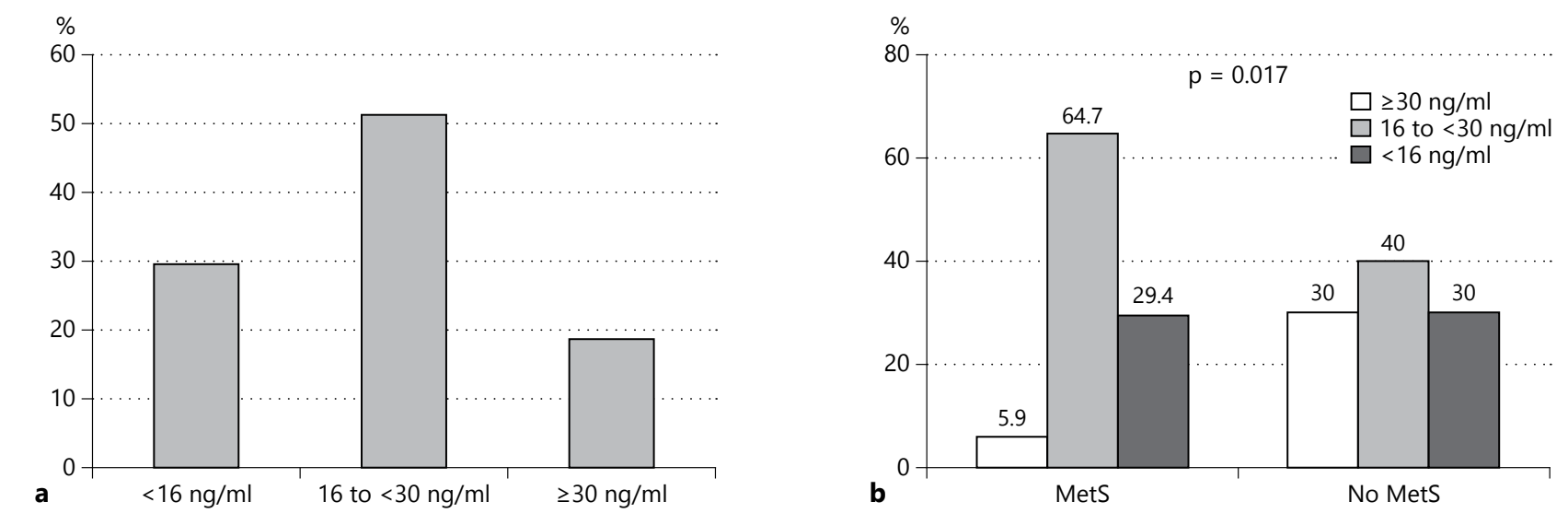

Fig. 1. 25[OH]D status: among study cohort (a) and according to the presence or not of MetS (b).

without MetS. Participants with MetS had higher BMI $(29.5 \pm 5.7$ vs. $26.2 \pm 4.8, p=0.01)$, were less likely to have received a living donor kidney transplant (38.2 vs. $60.0 \%$, $\mathrm{p}=0.06)$ and received slightly higher cumulative doses of CNIs (CsA: $41,221 \pm 13,665$ vs. $35,513 \pm 11,142 \mathrm{mg}$, $\mathrm{p}=$ 0.07; Tacro: $753 \pm 64$ vs. $436 \pm 66 \mathrm{mg}, \mathrm{p}=0.06$ ). The two groups of participants were otherwise similar with regard to age, gender, racial identity, the number of transplants, family history of T2D, positive hepatitis serology, smoking history, renal disease diagnosis, dialysis modalities and duration, fasting glucose levels prior to transplantation, the use of different calcineurin inhibitors, cumulative doses of corticosteroids, and the presence of delayed graft function.

The results of the levels of $25[\mathrm{OH}] \mathrm{D}$ during the third posttransplant months are as follows: $60(81.1 \%)$ had inadequate levels: $38(51.4 \%)$ insufficient $(16$ to $<30 \mathrm{ng} / \mathrm{ml})$ and $22(29.7 \%)$ deficient $(<16 \mathrm{ng} / \mathrm{ml})$ (fig. 1a) [18]. There was a significant inverse correlation between $25[\mathrm{OH}] \mathrm{D}$ and intact parathyroid hormone levels (Pearson correlation coefficients $\left.-0.3408, \mathrm{r}^{2} 0.116, \mathrm{p}<0.0001\right)$. Compared to patients without MetS, patients with MetS displayed significantly lower levels of $25[\mathrm{OH}] \mathrm{D}(20.5 \pm 7.2$, vs. $24.8 \pm 11.1 \mathrm{ng} / \mathrm{ml}, \mathrm{p}=0.049)$ with more patients having deficient/insufficient levels of 25[OH]D (94.1 vs. $70.0 \%$, $\mathrm{p}=0.017$ ) (fig. 1b). Stepwise multivariate logistical regression analysis demonstrated that, in addition to the independent negative association of MetS with 25[OH]D deficiency/insufficiency (OR: 14.0, 95\% CI: 1.8, 107.5; $\mathrm{p}=0.011$ ), a history of pretransplant dialysis and/or a longer duration of dialysis were also independently asso- ciated with $25[\mathrm{OH}] \mathrm{D}$ deficiency/insufficiency (OR: 5.2, 95\% CI: 1.2, 21.9, $\mathrm{p}=0.026$, and/or OR: $3.3,95 \% \mathrm{CI}: 1.3$, $8.1, \mathrm{p}=0.010$, respectively). We explored further the relationship between five elements of MetS and 25[OH]D status. None of the individual component criteria of MetS except a history of dialysis and/or the longer duration of dialysis were associated with $25[\mathrm{OH}] \mathrm{D}$ deficiency/insufficiency (data not shown).

Adiponectin, an adipose-tissue derived plasma protein, has been implicated in the homeostasis of glucose metabolism and IR $[10,11]$. We measured plasma adiponectin levels among the study participants. Patients with MetS had significantly lower levels of plasma adiponectin compared to patients without MetS $(8.2 \pm 4.5$ vs. $14.6 \pm$ $8.0 \mu \mathrm{g} / \mathrm{ml}, \mathrm{p}<0.0001$ ) (fig. 2a). Stepwise multivariate regression analysis confirmed a statistically significant negative association between either the presence of MetS or the numbers of MetS components and plasma adiponectin concentration ( $\beta$ estimate -6.39 and $-3.27, \mathrm{r}^{2} 0.195$ and $0.163, \mathrm{p}<0.0001$ and $\mathrm{p}=0.0004$, respectively) (fig. 2b). Other variables associated with low plasma adiponectin concentration included male gender and African-American race ( $\beta$ estimate -4.29 and $-3.25, \mathrm{r}^{2} 0.273$ and $0.315, p=0.007$ and 0.042 , respectively). Among the five components of MetS, only HDL-C levels and waist circumference were individually correlated with the plasma concentration of adiponectin ( $\beta$ estimate and $\mathrm{r}^{2}: 0.154$ and 0.164 for HDL-C with $\mathrm{p}=0.0004,-0.305$ and 0.232 for waist circumference with $\mathrm{p}=0.014$, respectively). However, there was no association between the plasma levels of $25[\mathrm{OH}] \mathrm{D}$ and those of adiponectin. The use of 


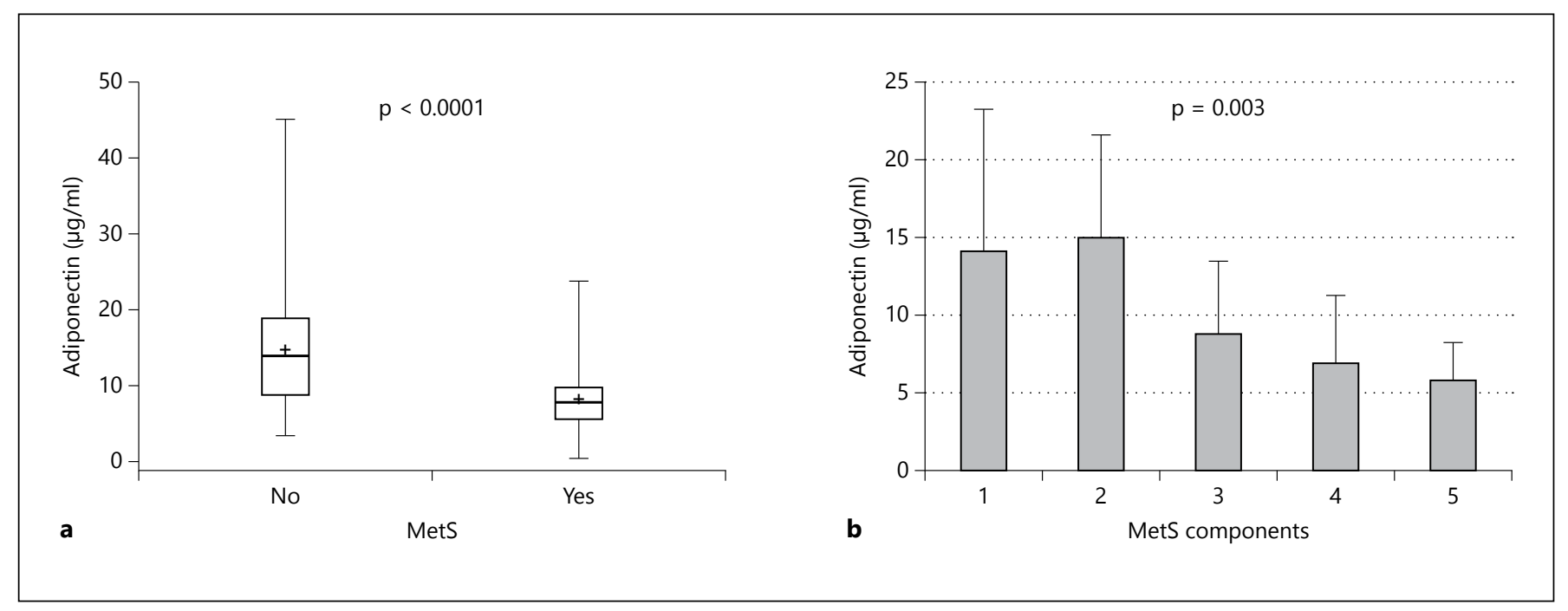

Fig. 2. Plasma adiponectin levels: between patients with and without MetS (a) and among patients with varying MetS components (b).

Table 2. Clinical information and laboratory parameters at the time of OGTT

\begin{tabular}{|c|c|c|c|}
\hline & \multicolumn{2}{|l|}{ MetS } & \multirow[t]{2}{*}{$\mathrm{p}$} \\
\hline & yes $(n=34)$ & no $(\mathrm{n}=40)$ & \\
\hline Winter season & $11(32.4)$ & $8(20.0)$ & 0.23 \\
\hline Vitamin D supplementation & $4(11.8)$ & $2(5.0)$ & 0.40 \\
\hline Calcium supplementation & $1(2.9)$ & $6(15.0)$ & 0.12 \\
\hline $25[\mathrm{OH}] \mathrm{D}, \mathrm{ng} / \mathrm{ml}$ & $20.5 \pm 7.2$ & $24.8 \pm 11.1$ & 0.049 \\
\hline iPTH, pg/ml & $148.4 \pm 186$ & $95.5 \pm 56.2$ & 0.12 \\
\hline Serum calcium, mg/dl & $9.6 \pm 0.6$ & $9.6 \pm 0.7$ & 0.90 \\
\hline Serum adiponectin, $\mu \mathrm{g} / \mathrm{ml}$ & $8.2 \pm 4.5$ & $14.6 \pm 8.0$ & $<0.0001$ \\
\hline Fasting glucose, $\mathrm{mg} / \mathrm{dl}$ & $100.7 \pm 13.7$ & $91.8 \pm 11.2$ & 0.004 \\
\hline Fasting insulin, $\mu \mathrm{U} / \mathrm{ml}$ & $29.1 \pm 23.3$ & $24.6 \pm 22.8$ & 0.40 \\
\hline HOMA-IR, & $7.2 \pm 5.8$ & $5.7 \pm 5.8$ & 0.28 \\
\hline $\begin{array}{l}\text { 2-hour OGTT glucose } \\
\mathrm{mg} / \mathrm{dl}\end{array}$ & $133.5 \pm 45.0$ & $112.9 \pm 35.1$ & 0.03 \\
\hline $\begin{array}{l}\text { Glycated hemoglobin } \\
\quad 1 \mathrm{c}, \mathrm{A} 1 \mathrm{c}\end{array}$ & $5.5 \pm 0.6$ & $5.4 \pm 0.5$ & 0.25 \\
\hline Uric acid, mg/dl & $7.1 \pm 1.2$ & $6.2 \pm 1.6$ & 0.01 \\
\hline Use of allopurinol & $5(14.7)$ & $5(12.5)$ & 0.78 \\
\hline Triglyceride, mg/dl & $224.8 \pm 94.9$ & $127.3 \pm 49.6$ & $<0.001$ \\
\hline HDL-C, mg/dl & $45.4 \pm 13.5$ & $57.0 \pm 16.8$ & 0.002 \\
\hline LDL-C, mg/dl & $131.1 \pm 35.0$ & $117.1 \pm 44.5$ & 0.13 \\
\hline Use of statins & $5(14.7)$ & $5(12.5)$ & 0.78 \\
\hline Systolic BP, mm Hg & $132.2 \pm 17.5$ & $134.6 \pm 16.4$ & 0.55 \\
\hline Diastolic BP, mm Hg & $76.0 \pm 9.2$ & $77.3 \pm 9.2$ & 0.54 \\
\hline Pulse pressure, $\mathrm{mm} \mathrm{Hg}$ & $56.2 \pm 16.3$ & $57.3 \pm 15.8$ & 0.78 \\
\hline Hypertension drugs, $\mathrm{n}$ & $1.8 \pm 0.9$ & $1.6 \pm 0.8$ & 0.29 \\
\hline
\end{tabular}

Values are means \pm SD or $\mathrm{n}(\%) . \mathrm{iPTH}=$ Intact parathyroid hormone; OGTT $=$ oral glucose tolerance test. immunosuppressive drugs (neither the type of CNIs nor the cumulative doses of CNIs and corticosteroids) had no effect on the plasma concentration of adiponectin (data not shown).

IR, measured as HOMA-IR, is considered the hallmark of MetS [19]. We found HOMA-IR higher among the participants with MetS than without $(7.2 \pm 5.8$ vs. $5.7 \pm 5.8$ ), though the difference was not statistically significant in either univariate or multivariate analysis ( $\mathrm{p}=0.28$ and $\mathrm{p}=0.11$, respectively). Other laboratory parameters are shown in table 2. Although there was no difference in the levels of glycosylated hemoglobin, the 2-hour postchallenge glucose levels were considerably higher among the study participants with MetS than those without $(133.5 \pm 45.0$ vs. $112.9 \pm 35.1 \mathrm{mg} / \mathrm{dl}, \beta$ estimate 18.63, $\left.\mathrm{r}^{2} 0.037, \mathrm{p}=0.056\right)$.

During the follow-up, 10 patients developed NODAT, 7 patients suffered CVEs, 20 patients had acute rejection and 8 kidney grafts were lost including 2 deaths with graft function. Table 3 shows the distribution of events between patients with and without MetS. Due to limited sample size with small numbers of individual events, we combined all patients with any event and used this as a composite endpoint. Patients with MetS at 11 weeks were more likely to have an event during subsequent follow-up than patients without MetS (61.8 vs. $27.5 \%, \mathrm{p}=0.003$ ). Multivariate logistic regression analysis confirmed an independent association of MetS with subsequent development of an event (OR: 5.6, 95\% CI: 1.9, 16.5; $\mathrm{p}=0.002$ ). The plasma concentration of $25[\mathrm{OH}] \mathrm{D}$ and adiponectin, 
Table 3. Clinical outcomes

\begin{tabular}{lccl}
\hline & \multicolumn{2}{c}{ MetS } & $\mathrm{p}$ \\
\cline { 2 - 3 } & yes $(\mathrm{n}=34)$ & no $(\mathrm{n}=40)$ & \\
\hline CVE & & & \multirow{2}{*}{0.24} \\
$\quad$ MI & $2(5.9)$ & $0(0.0)$ & \\
$\quad$ Angina & $2(5.9)$ & $1(2.5)$ & \\
CHF & $1(2.9)$ & $1(2.5)$ & \\
NODAT & $8(25.3)$ & $2(5.0)$ & 0.04 \\
Acute rejection & $12(35.3)$ & $8(20.0)$ & 0.14 \\
Graft loss & $6(17.6)$ & $2(5.0)$ & 0.08 \\
Patients with any event ${ }^{1}$ & $21(61.8)$ & $11(27.5)$ & 0.003 \\
eGFR, ml/min & $53.9 \pm 21.2$ & $57.1 \pm 18.7$ & 0.52 \\
\hline
\end{tabular}

Values are means $\pm \mathrm{SD}$ or $\mathrm{n}(\%) . \mathrm{CHF}=$ Congestive heart failure; eGFR = estimated glomerular filtration rate; $\mathrm{MI}=$ myocardial infarction; NODAT $=$ new-onset diabetes mellitus after transplantation. ${ }^{1}$ Some patients had $>1$ event.

on the other hand, were not independently associated with future event risk (data not shown). Renal function was not statistically different between the groups.

\section{Discussion}

We have previously shown that MetS is highly prevalent early after kidney transplantation among nondiabetic patients and was associated with abnormal glucose homeostasis [15]. In the current study, we show that patients with MetS early posttransplantation have significantly lower plasma levels of 25[OH]D and adiponectin. However, it is the presence of MetS, not the lower levels of $25[\mathrm{OH}] \mathrm{D}$ and adiponectin, that was independently associated with the risk of future clinical events.

MetS has been associated with increased risk of diabetes mellitus and CVEs in the general population. The pathogenic mechanism underlying such association includes IR likely due to the presence of low-grade chronic inflammation, deficiency in certain nutritional and/or hormonal elements, such as vitamin D and adiponectin $[8,11,19-21]$. Inadequate blood levels of vitamin $\mathrm{D}$ are common in the general population and present among $80-97 \%$ of stable kidney transplant patients $[5,7,11]$. Vitamin D deficiency not only causes impairment in calcium and bone metabolism, but also increases risks of many chronic medical conditions in the general population $[20,22,23]$. In subjects with MetS, lower levels

Early Posttransplant Precursors of Metabolic Disorders of vitamin D predicted all-cause and cardiovascular disease mortality [24]. Although our study did not find an independent negative association of vitamin deficiency/ insufficiency with negative clinical outcomes which could be related to the small sample size with limited follow-up, based on the magnitude of vitamin D deficiency/insufficiency, its association with MetS and its many putative salutary effects, the role of its supplementation should be investigated in the kidney transplant patient population.

Adiponectin is adipokine that positively affects lipid and glucose metabolism [9]. The plasma concentration of adiponectin is inversely correlated with the risk of impaired glucose tolerance and $\mathrm{T} 2 \mathrm{D}$, premature coronary artery disease and MetS [10, 12-14, 25]. Our study confirmed the previous findings of an independent association between hypoadiponectinemia and MetS. Furthermore, only 2 out of 5 elements of MetS, HDL-C levels and waist circumference showed a significant correlation with the plasma concentration of adiponectin. However, we could not demonstrate a significant association between plasma concentration of adiponectin and IR as previously reported [13, 25]. Furthermore, we found no influence of immunosuppressive drugs on the plasma concentration of adiponectin.

Our study has several important limitations. First, it is an observational study which precluded us from drawing any cause-effect relationship between the presence of MetS and the observed laboratory and clinical parameters. Second, our study involved only a small number of patients with relatively young age and short follow-up period, which could explain the fewer cases of CVEs observed and the lack of association between the lower levels of $25[\mathrm{OH}] \mathrm{D}$ and adiponectin and negative clinical outcomes. Alternatively, the lower levels of $25[\mathrm{OH}] \mathrm{D}$ and adiponectin could represent an epiphenomenon of MetS rather than potential mechanisms through which MetS exercises its negative clinical impact. Finally, we measured only serum concentrations of total adiponectin which does not discriminate highfrom low-molecule-weight forms and thus we were unable to determine which form of adiponectin was associated with MetS.

In conclusion, nondiabetic kidney transplant recipients with MetS have a low plasma concentration of $25[\mathrm{OH}] \mathrm{D}$ and adiponectin. The presence of MetS early after transplantation was associated with inferior clinical outcomes during a relatively short follow-up period. Additional studies involving a larger kidney transplant patient population and with longer follow-up are needed to 
determine whether the reported association has an etiologic role and whether vitamin D supplementation or other therapeutic interventions can mitigate the high prevalence of MetS in the kidney transplant population and counteract its negative impact on long-term clinical outcomes.

\section{Acknowledgements}

This work was accepted for oral presentation at the American Transplant Congress 2012, June 2-6, Boston, Mass., USA. Funding/financial support was provided by the Institutional Discretional Research Fund, Department of Internal Medicine, University of Michigan. This work utilized the Chemistry Laboratory of the MDRTC funded by NIH5P60 DK20572 from the National Institute of Diabetes and Digestive and Kidney Diseases.

\section{References}

$\checkmark 1$ de Vries AP, Bakker SJ, van Son WJ, van der Heide JJ, Ploeg RJ, The HT, de Jong PE, Gans RO: Metabolic syndrome is associated with impaired long-term renal allograft function; not all component criteria contribute equally. Am J Transplant 2004;4:1675-1683.

-2 Luan FL, Langewisch E, Ojo A: Metabolic syndrome and new onset diabetes after transplantation in kidney transplant recipients. Clin Transplant 2010;24:778-783.

$>3$ Porrini E, Delgado P, Bigo C, Alvarez A, Cobo M, Checa MD, Hortal L, Fernandez A, Garcia JJ, Velazquez S, Hernandez D, Salido E, Torres A: Impact of metabolic syndrome on graft function and survival after cadaveric renal transplantation. Am J Kidney Dis 2006;48: 134-142.

$>4$ Courivaud C, Kazory A, Simula-Faivre D, Chalopin JM, Ducloux D: Metabolic syndrome and atherosclerotic events in renal transplant recipients. Transplantation 2007; 83:1577-1581.

5 Holick MF: Vitamin D deficiency. N Engl J Med 2007;357:266-281.

6 Dobnig H, Pilz S, Scharnagl H, Renner W, Seelhorst U, Wellnitz B, Kinkeldei J, Boehm BO, Weihrauch G, Maerz W: Independent association of low serum 25-hydroxyvitamin d and 1,25-dihydroxyvitamin d levels with allcause and cardiovascular mortality. Arch Intern Med 2008; 168:1340-1349.

7 Stavroulopoulos A, Cassidy MJ, Porter CJ, Hosking DJ, Roe SD: Vitamin D status in renal transplant recipients. Am J Transplant 2007;7:2546-2552.

$>8$ Kayaniyil S, Vieth R, Harris SB, Retnakaran R, Knight JA, Gerstein HC, Perkins BA, Zinman B, Hanley AJ: Association of 25(OH)D and PTH with metabolic syndrome and its traditional and nontraditional components. J Clin Endocrinol Metab 2011;96:168-175.

$>9$ Kadowaki T, Yamauchi T, Kubota N, Hara K, Ueki K, Tobe K: Adiponectin and adiponectin receptors in insulin resistance, diabetes, and the metabolic syndrome. J Clin Invest 2006; 116:1784-1792.
10 Snijder MB, Heine RJ, Seidell JC, Bouter LM, Stehouwer CD, Nijpels G, Funahashi T, Matsuzawa Y, Shimomura I, Dekker JM: Associations of adiponectin levels with incident impaired glucose metabolism and type 2 diabetes in older men and women: the Hoorn study. Diabetes Care 2006;29:2498-2503.

11 Tajtakova M, Petrasova D, Petrovicova J, Pytliak M, Semanova Z: Adiponectin as a biomarker of clinical manifestation of metabolic syndrome. Endocr Regul 2006;40:15-19.

12 Lee MC, Lee CJ, Chou KC, Shih MH, Hsu BG: Hypoadiponectinemia correlates with metabolic syndrome in kidney transplantation patients. Transplant Proc 2011;43:2601-2605.

$>13$ Hjelmesaeth J, Flyvbjerg A, Jenssen T, Frystyk J, Ueland T, Hagen M, Hartmann A: Hypoadiponectinemia is associated with insulin resistance and glucose intolerance after renal transplantation: impact of immunosuppressive and antihypertensive drug therapy. Clin J Am Soc Nephrol 2006;1:575-582.

14 Filippi E, Sentinelli F, Romeo S, Arca M, Berni A, Tiberti C, Verrienti A, Fanelli M, Fallarino $M$, Sorropago G, Baroni MG: The adiponectin gene $\mathrm{SNP}+276 \mathrm{G}>\mathrm{T}$ associates with early-onset coronary artery disease and with lower levels of adiponectin in younger coronary artery disease patients (age <or $=50$ years). J Mol Med 2005;83:711-719.

15 Luan FL, Stuckey LJ, Ojo AO: Abnormal glucose metabolism and metabolic syndrome in non-diabetic kidney transplant recipients early after transplantation. Transplantation 2010;89:1034-1039.

16 Third Report of the National Cholesterol Education Program (NCEP) Expert Panel on Detection, Evaluation, and Treatment of High Blood Cholesterol in Adults (Adult Treatment Panel III) final report. Circulation 2002;106: 3143-3421.
17 Albareda M, Rodriguez-Espinosa J, Murugo M, de Leiva A, Corcoy R: Assessment of insulin sensitivity and beta-cell function from measurements in the fasting state and during an oral glucose tolerance test. Diabetologia 2000;43:1507-1511.

$18 \mathrm{~K} / \mathrm{DOQI}$ clinical practice guidelines for bone metabolism and disease in chronic kidney disease. Am J Kidney Dis 2003;42(4 suppl 3):S1-S201.

19 Reaven GM: Banting lecture 1988. Role of insulin resistance in human disease. Diabetes 1988;37:1595-1607.

20 Devaraj S, Jialal G, Cook T, Siegel D, Jialal I: Low vitamin D levels in Northern American adults with the metabolic syndrome. Horm Metab Res 2011;43:72-74.

21 Ingelsson E, Hulthe J, Lind L: Inflammatory markers in relation to insulin resistance and the metabolic syndrome. Eur J Clin Invest 2008;38:502-509.

22 Gagnon C, Lu ZX, Magliano DJ, Dunstan DW, Shaw JE, Zimmet PZ, Sikaris K, Grantham N, Ebeling PR, Daly RM: Serum 25-Hydroxyvitamin $\mathrm{D}$, calcium intake, and risk of type $2 \mathrm{dia}$ betes after 5 years: results from a national, population-based prospective study (the Australian Diabetes, Obesity and Lifestyle study). Diabetes Care 2011;34:1133-1138.

-23 Melamed ML, Michos ED, Post W, Astor B: 25-hydroxyvitamin D levels and the risk of mortality in the general population. Arch Intern Med 2008;168:1629-1637.

24 Thomas GN, ó Hartaigh B, Bosch JA, Pilz S, Loerbroks A, Kleber ME, Fischer JE, Grammer TB, Bohm BO, März W: Vitamin D levels predict all-cause and cardiovascular disease mortality in subjects with the metabolic syndrome: the Ludwigshafen Risk and Cardiovascular Health (LURIC) Study. Diabetes Care 2012;35:1158-1164.

-25 Hung J, McQuillan BM, Thompson PL, Beilby JP: Circulating adiponectin levels associate with inflammatory markers, insulin resistance and metabolic syndrome independent of obesity. Int J Obes (Lond) 2008;32:772-779. 